\title{
Extraction of phytocompounds from the medicinal plant Clinacanthus nutans Lindau by microwave-assisted extraction and supercritical carbon dioxide extraction
}

\author{
Ana N. Mustapa ${ }^{a, b}$, Ángel Martin ${ }^{a, *}$, Rafael B. Mato ${ }^{a}$, María José Cocero ${ }^{a}$ \\ ${ }^{a}$ University of Valladolid, Industrial Engineering School, Department of Chemical Engineering and Environmental Technology, High Pressure Processes \\ Group, C/Dr. Mergelina, s/n, 47011 Valladolid, Spain \\ ${ }^{\mathrm{b}}$ Faculty of Chemical Engineering, Universiti Teknologi MARA, 40450 Shah Alam Selangor, Malaysia
}

\section{A R T I C L E I N F O}

\section{Article history:}

Received 15 December 2014

Received in revised form 24 March 2015

Accepted 17 April 2015

Available online 23 May 2015

\section{Keywords:}

Microwave-assisted extraction (MAE)

Supercritical fluid extraction

Soxhlet

Flavonoids

polyphenols

Snake grass

\begin{abstract}
A B S T R A C T
The composition and bioactivity of natural plant extracts strongly depends on the extraction technique employed. Clinacanthus nutans Lindau (C. nutans) is a well-known medicinal plant in South-East Asia that has been traditionally used for treatment of hepatitis, skin-rashes and snake venom poisoning, and recently has attracted attention for its applications for treatment and prevention of cancer diseases. In previous studies, the extraction of bioactive compounds from $C$. nutans by conventional Soxhlet solvent extraction has been described, but this method shows limitations in terms of selectivity, extraction yield and toxicity of the solvents employed. In this study, phytochemical compounds were extracted from leaves and stems of $C$. nutans by microwave-assisted extraction (MAE), pressurized microwave-assisted extraction (PMAE), supercritical carbon dioxide extraction (SFE) and Soxhlet method to investigate the best technique in terms of yield, extraction time and recovery of bioactive compounds: phenols, flavonoids, phytosterols and $\beta$-sitosterol. The extracted phytocompounds and phenolics were characterized by gas chromatography mass spectrometry (GC/MS) and ultra performance liquid chromatography (UPLC). The results showed that MAE was the best technique to achieve a high yield and a maximal total polyphenol content $(11.30 \pm 0.39 \mathrm{mg} \mathrm{GAE} / \mathrm{g} \mathrm{DM}$ ) and flavonoids content (and $4.66 \pm 0.20 \mathrm{mg} \mathrm{GAE} / \mathrm{g}$ $\mathrm{DM})$, whereas SFE was the best method for phytosterols and $\beta$-Sitosterol extraction. P-MAE merely enhanced the polyphenol and flavonoids yield to $14.56 \pm 0.77 \mathrm{mg} \mathrm{GAE} / \mathrm{g} \mathrm{DM}$ and $5.29 \pm 0.30 \mathrm{mg} \mathrm{QE} / \mathrm{g}$ DM respectively, without significant variations on the type of compounds obtained. MAE appears as the most efficient technique for the extraction of phytochemical compounds from $C$. nutans in a short time with a reasonable yield and a good selectivity toward bioactive nutraceutical compounds, with high concentrations of antioxidants, anti-inflammatory and antimicrobial compounds.
\end{abstract}

(c) 2015 Elsevier B.V. All rights reserved.

\section{Introduction}

Clinacanthus nutans Lindau (C. nutans), commonly known as snake grass, is a medicinal herb belonging to the family of Acanthaceae widely grown in the tropical region, mainly in Southeast Asia. It has been traditionally used as herbal medicine for treatment of herpes infection, insect and snake bites and allergic responses (Sakdarat et al., 2009; Tuntiwachwuttikul et al., 2004; Wanikiat et al., 2008). Its uses in traditional medicine have been scientifically supported by numerous studies that demonstrate that $C$. nutans extracts show anti-inflammatory, antimicrobial

\footnotetext{
* Corresponding author. Tel.: +34 983423174.

E-mail address: mamaan@iq.uva.es (Á. Martin).
}

and anti-viral activity against herpes simplex virus (HSV) and varicella-zoster virus (VZV) lesions (Charuwichitratana et al., 1996; Janwitayanuchit et al., 2003; Sakdarat et al., 2009; Yoosook et al., 1999). In Thailand, the plant has been accepted as an essential medicinal herb for primary healthcare by the Ministry of Public Health of the country after extensive research on the $C$. nutans medicinal properties (Wanikiat et al., 2008). Moreover, in recent years, $C$. nutans has attracted considerable research interest due to its alleged properties for cancer treatment (Putwatana et al., 2009; Yong et al., 2013; Yuann et al., 2012).

Various factors must be examined in order to determine the effectiveness of medicinal herb extracts. Among them, the extraction technique employed to obtain the bioactive compounds from the plant is a key factor. This is because, the efficiency of extraction of different bioactive compounds from plant materials is 
influenced by several factors, such as solvent polarity and concentration, solvent-to-feed ratio, extraction time and thermal degradation. In addition, a reasonable sample preparation is also very important to prevent the deterioration of the plant extract. For example, the use of activated charcoal to remove interferences, such as chlorophyll in plant extracts, reported in some previous works, should be avoided. We have found in preliminary experiments of this work that treatment with activated charcoal eliminates many phytocompounds from the medicinal plant, thus, reducing the potential biological activity of the extract.

In previous studies, $C$. nutans was treated by Soxhlet technique using methanol, chloroform, ethanol and hexane as solvents. Depending on the solvent employed, the bioactive constituents of C. nutans extracts were discovered to comprise stigmasterol, $\beta$ sitosterol, lupeol (Dampawan et al., 1977), betulin (Lin et al., 1983), six known $C$-glycosyl flavones, vitexin, isovitexin, shaftoside, isomollupentin, 7-O- $\beta$-glucopyranoside, orientin, isoorientin (Teshim et al., 1997), sulfur containing glucosides (Teshima et al., 1998), glycoglycerolipids, a mixture of nine cerebrosides, monoacylmonogalactosylglycerol (Tuntiwachwuttikul et al., 2004).

From these previous studies, it can be concluded that to date, only simple maceration and Soxhlet extraction techniques have been reported for extraction of bioactive compounds from $C$. nutans medicinal herbs. In this work, it is hypothesized that the composition and properties of the extract are highly dependent on extraction method as well as on the solvent employed. The application of enhanced extraction techniques with non-toxic solvents (supercritical carbon dioxide extraction and microwave-assisted extraction MAE with ethanol-water solvent mixtures) on C. nutans is reported for the first time and compared with the conventional Soxhlet extraction method. Supercritical fluid extraction is a wellknown method for producing high quality plant extracts in a safe and clean way. On the other hand, MAE extraction has been developed as a simple, faster and less solvent consumption method for the production of high valuable extracts from plant materials. In addition, we introduced the use of pressure in microwave-assisted extraction (P-MAE) to further enhance the extraction of phytocompounds from the medicinal plant. Theoretically, increases of pressure and the corresponding increments in extraction temperature could increase the solubility of the bioactive compounds in the extracting solvent.

The aim of this study is to determine the best technique for the extraction of phytocompounds from $C$. nutans, considering the extraction yield and the content on significant phytocompounds: phenols, flavonoids, phytosterols and $\beta$-sitosterol. Chlorophyll content in the $C$. nutans was also determined as complement to the phytocompounds characterization, regardless the effect of extraction technique. In addition, the phenolic compounds in $C$. nutans extracts were characterized by ultra-performance liquid chromatography (UPLC) coupled to electrospray ionization and quadrupole-time of flight-mass spectrometry (ESI-QTOF/MS). This study is the first work reporting on the effect of modern extraction techniques on the phytocompounds and the characterization of phenolic compounds present in C.nutans extract based on the UPLC-ESI-QTOF/MS analysis.

\section{Experimental}

\subsection{Materials}

$\beta$-sitosterol (analytical chromatography grade), gallic acid, quercetin (analytical grade) and ethanol (96\%) were purchased from Sigma-Aldrich Co. (Spain). Water was purified by a MilliQ water purifier system from Millipore (Milford, MA, USA). The Folin-Ciocalteu reagent was obtained from Merck (Darmstadt,
Germany). Dried C. nutans (Burm.f.) Lindau samples were purchased from Mr. Lee Huat Lye Kuala Lumpur, Malaysia.

\subsection{Sample preparation}

The total moisture content of leaves and stems was determined gravimetrically by air drying in an oven set at $105^{\circ} \mathrm{C}$ for $24 \mathrm{~h}$. Prior to extraction, samples were dried in the oven at $60^{\circ} \mathrm{C}$ for $2 \mathrm{~h}$, in order to reduce the moisture content, ground and sieved to a particle size in the range of $500-100 \mu \mathrm{m}$. The prepared samples were then stored in airtight bags, swept with nitrogen gas and kept in a refrigerator $\left(-8^{\circ} \mathrm{C}\right)$ until used in extraction experiments.

\subsection{Microwave-assisted extraction (MAE) and pressurised-MAE $(P-M A E)$}

MAE and P-MAE were carried out in a laboratory CEM Discover ${ }^{\circledR}$ microwave oven ( $300 \mathrm{~W}$ maximum power) operating at a frequency of $2.45 \mathrm{GHz}$, using ethanol-water solvent mixtures. The microwave oven was equipped with an optical fiber probe to measure the real temperature profile during the extraction process. MAE was operated as an open system whereas P-MAE was performed in closed system. Microwave irradiation in P-MAE was terminated when 2.7 bar of pressure build-up in the system was achieved. The parameters studied were the concentration of the ethanol-water solution (44-86 vol\%) with a solvent-to-feed ratio of $14 \mathrm{~g} / \mathrm{g}$, at a constant power of $300 \mathrm{~W}$. The extraction time $(5,10$, 15 , and $20 \mathrm{~s}$ ) was determined in preliminary experiments to find an appropriate relation of temperature-time at a fixed irradiation power and to identify a sufficient time to achieve a temperature close to the boiling point of the ethanol-sample system at a constant irradiation power of $300 \mathrm{~W}$. From the preliminary study, it was found that $15 \mathrm{~s}$ was sufficient to achieve ethanol's boiling point at $300 \mathrm{~W}$ based on solvent-to-feed ratio of 14 .

In extraction experiments, about $1.0000 \pm 0.0002 \mathrm{~g}$ of $C$. nutans sample was mixed with $14 \mathrm{~mL}$ of ethanol-water solution (44-86 vol\%) in a $100 \mathrm{~mL}$ round-bottom flask. The mixed ethanol-sample material system was kept under magnetic stirring for $3 \mathrm{~min}$ to allow the samples to be soaked by the solvent. This promotes the diffusion of the solvent into the sample matrix and improves the mass transfer of active compounds into the solvent. During the microwave irradiation, the ethanol-sample was constantly stirred using a magnetic stirrer to avoid the formation of hot spots within the sample, thus, homogenizing the temperature of the mixture during the extraction process. After irradiated by MAE, the sample was rapidly cooled down to $40^{\circ} \mathrm{C}$ in an ice bath, $6 \mathrm{~mL}$ of cold fresh ethanol was added to the sample and the experiment proceeded with a conventional extraction in warm water $\left(40^{\circ} \mathrm{C}\right)$ for $80 \mathrm{~min}$. Prior to the sample collection, nitrogen gas was flowed into the amber vials used to store the sample to remove air. Extracts were subjected to filtration using $0.20 \mu \mathrm{m}$ PTFE to remove solid residues before storage.

\subsection{Supercritical fluid extraction (SFE)}

The supercritical fluid extraction of $C$. nutans was carried out over $80 \mathrm{~g}$ of $C$. nutans (7-8 wt\% of moisture) at 350 bar and $60^{\circ} \mathrm{C}$ in a custom-made SFE setup (Fig. 1). The system consisted of an extraction vessel made of stainless steel with a volume of $4 \mathrm{~L}$, height of $49.5 \mathrm{~cm}$ and inner diameter of $9.7 \mathrm{~cm}$. Pressure in the vessel was regulated by means of a back-pressure GO valve installed in the line between the extraction vessel and the separator. The reduction of pressure with this valve causes the transition from a supercritical to a gaseous $\mathrm{CO}_{2}$ state, and therefore, the separation of the compounds extracted from $\mathrm{CO}_{2}$ by condensation and precipitation. The separator was a vessel of $2.5 \mathrm{~L}$, designed to generate a cyclonic flow 


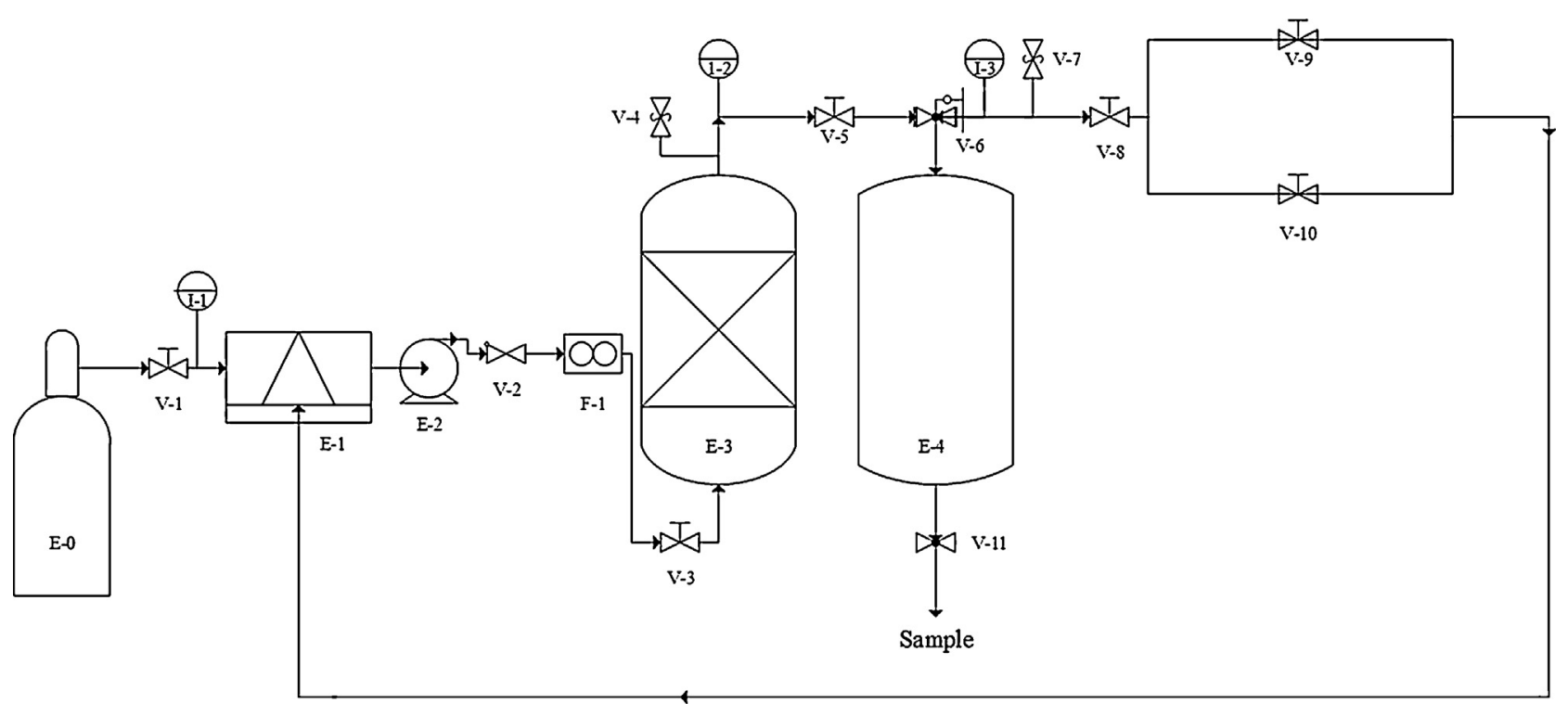

Fig. 1. Supercritical fluid extraction plant. E-0: $\mathrm{CO}_{2}$ tank, E-1: refrigerator, E-2: pump, E-3: extractor, E-4: separator, F-1: gas flowmeter.

pattern and equipped with a heating/cooling jacket that can be used to adjust the temperature desired for an optimum separation of the extracted compounds from $\mathrm{CO}_{2} \cdot \mathrm{CO}_{2}$ was pressurized by means of a diaphragm pump. The system operated in a closed $\mathrm{CO}_{2}$ circuit, and gaseous $\mathrm{CO}_{2}$ leaving the separator was condensed in a cooler operating at $-25^{\circ} \mathrm{C}$ and recompressed with the pump into the extractor. Temperature and pressure conditions in the extraction apparatus were monitored through probes connected to a Picolog data acquisition software, and the amount of $\mathrm{CO}_{2}$ consumed was measured by a Coriolis gas flowmeter.

In a SFE experiment, the extraction vessel was filled with the dried sample of $C$. nutans, covered at top and bottom with a mesh filter. Before the extraction started, the apparatus was flushed with $\mathrm{CO}_{2}$ to remove air from the system, and afterwards the extraction vessel was filled with $\mathrm{CO}_{2}$ up to the desired operating pressure and temperature ( $350 \mathrm{bar}$ and $60^{\circ} \mathrm{C}$ ). After reaching these conditions, the back pressure valve between extractor and separator was regulated in order to maintain the conditions at the separator at $50 \mathrm{bar}$ and $40^{\circ} \mathrm{C}$ to achieve an efficient extract- $\mathrm{CO}_{2}$ separation. The extraction proceeded for a total time of $120 \mathrm{~min}$ with a $\mathrm{CO}_{2}$ flowrate of $9 \mathrm{~kg} / \mathrm{h}$. Finally, the system was depressurized and a sample of the extract was taken from the separator. The sample was collected in an amber vial to protect it from light, weighed and stored in a refrigerator $\left(-8^{\circ} \mathrm{C}\right)$ until analysis.

\subsection{Soxhlet extraction}

Solvent extraction was carried out in a Soxhlet apparatus for $8 \mathrm{~h}$ using $80 \mathrm{~mL}$ of absolute ethanol over about $3.0 \mathrm{~g}$ of dry plant. Afterwards, extracts were subjected to rotary vacuum evaporation (Heidolph) at $40^{\circ} \mathrm{C}$ to remove the solvent from the oil. The extracts were weighed and stored in an amber vials and kept in a refrigerator $\left(-8^{\circ} \mathrm{C}\right)$ until analysis.

\subsection{Gas chromatography mass spectrometry (GC/MS) analysis}

The phytochemical composition of C. nutans extract was analyzed on an Agilent gas chromatograph model 6890 (Agilent Technologies, J\&W Scientific Products, Palo Alto, CA, USA) equipped with an Agilent 122-7032 capillary column, DB-WAX $(30 \mathrm{~m} \times 0.25 \mathrm{~mm} \times 0.25 \mu \mathrm{m})$ and coupled to a mass selective detector (MSD5973) working at $70 \mathrm{eV}$ of ionization voltage. Helium was used as a carrier gas at $1.0 \mathrm{~mL} / \mathrm{min}$ with injection in splitless mode. The oven temperature was programmed as follows: $110^{\circ} \mathrm{C}$ held during $3 \mathrm{~min}$, then increased to $200^{\circ} \mathrm{C}$ at rate of $5^{\circ} \mathrm{C} / \mathrm{min}$, then increased to $250^{\circ} \mathrm{C}$ at rate of $10^{\circ} \mathrm{C} / \mathrm{min}$ and finally maintained at $250^{\circ} \mathrm{C}$ for $10 \mathrm{~min}$. Components identification was made based on comparison of their mass spectra with those in Wiley Registry of Mass Spectral Data, 7th edition (Agilent Technologies, Inc.) and National Institute of Standards and Technology 05 MS (NIST) mass spectral library data.

\subsection{High performance liquid chromatography (HPLC) analysis}

A reversed-phase and isocratic HPLC method was set up to analyze the $\beta$-sitosterol content in extracts. The HPLC apparatus consisted of pump (515HPLC pump waters), waters 717 plus autosampler, waters 432 conductivity detector, waters 2487 dual $\lambda$ absorbance detector and column (symmetry C18 $5 \mu \mathrm{m}$, $4.6 \times 150 \mathrm{~mm})$. The mobile phase was methanol/2-propanol $(4: 1$ $\mathrm{v} / \mathrm{v}$ ) at a flowrate of $0.7 \mathrm{~mL} / \mathrm{min}$ and the injection volume was $20 \mu \mathrm{L}$ in each analysis. $\beta$-sitosterol was detected by an evaporating light scattering detector (ELSD) and the chromatogram was monitored at a UV wavelength of $210 \mathrm{~nm}$. In order to quantify the amount of $\beta$-sitosterol in the sample, a linear calibration curve was developed based on standard solutions of $\beta$-sitosterol at six different concentrations, in the range $50-500 \mathrm{mg} / \mathrm{L}$. About $0.005 \mathrm{~g}$ of oil extracts from SFE experiments was diluted with methanol $(4 \mathrm{~mL})$. For MAE sample, the extracts were subjected to saponification technique prior to the HPLC analysis.

\subsection{Chlorophyll analysis}

C. nutans has been reported to contain chlorophyll a and b (Sakdarat et al., 2009). To determine the total chlorophyll content in C. nutans, ethanol (abs) and acetone (abs) solvents were used in the MAE at $300 \mathrm{~W}$ for $15 \mathrm{~s}$. The sample extracts were filtered and subjected to UV-vis spectrophotometer detection. Total concentrations of chlorophyll a and b were determined by measuring the absorbance using a UV-vis spectrophotometer. The equations proposed by Wintermans and de Mots (1965) for ethanol and by Wellburn (1994) for acetone were used to evaluate the chlorophyll concentration. 


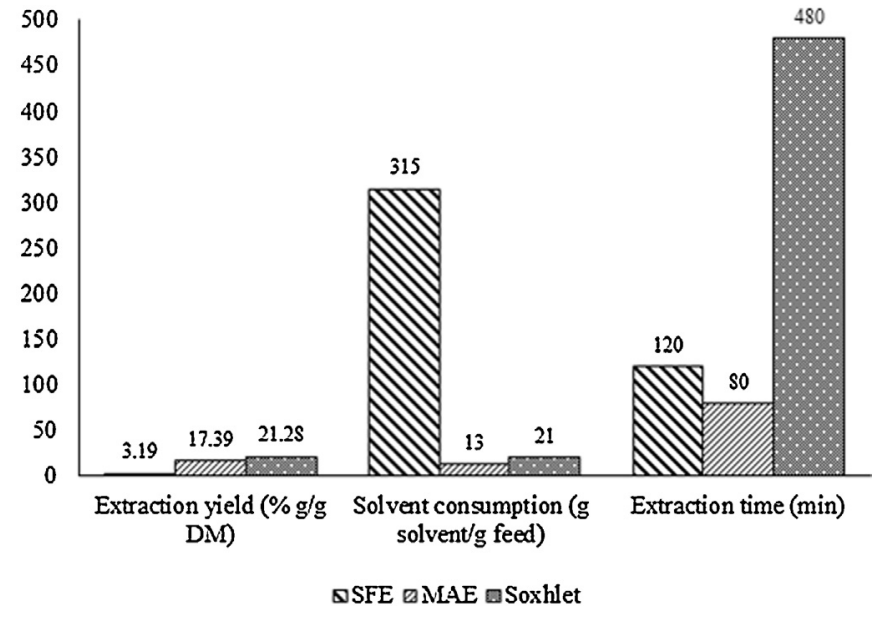

Fig. 2. Comparison of the extraction yield, solvent consumption and extraction time corresponding to the different extraction techniques employed.

\subsection{Total phenol content (TPC) analysis}

The total phenolic content in the SSG extracts was determined by the Folin-Ciocalteu colorimetric method and expressed as gallic acid equivalents (GAE) per gram of dry material (mg GAE/g dried material, DM) (Sólyom et al., 2014). For this, $40 \mu \mathrm{L}$ of sample extracts were mixed with $3 \mathrm{~mL}$ of distilled water followed by addition of $200 \mu \mathrm{L}$ of Folin-Ciocalteu reagent under gentle stirring. After $5 \mathrm{~min}, 600 \mu \mathrm{L}$ of saturated $\mathrm{Na}_{2} \mathrm{CO}_{3}$ solution was added, shaken gently and incubated in a warm water bath $\left(40^{\circ} \mathrm{C}\right)$ for $30 \mathrm{~min}$. Absorbance was measured at $765 \mathrm{~nm}$ (UV-2550 Shidmadzu UV-vis spectrometer). Standard solutions of known concentration of gallic acid (50-900 ppm) were used for calibration.

\subsection{Total flavonoids content}

Prior to the flavonoids determination, it is necessary to eliminate chlorophyll from ethanolic extracts as it causes interference. Some authors suggest to use activated charcoal to eliminate the chlorophyll color. However, from our preliminary trials we found that the use of charcoal for more than $2 \mathrm{~h}$ to remove any interference traces including chlorophyll in the $C$. nutans extract significantly reduced the phenols content from 5.54 to $1.51 \mathrm{mg} \mathrm{GAE} / \mathrm{g}$ dried material (DM). Thus, use of charcoal may cause deficiency on the therapeutic strength as some bioactive compounds from medicinal plant extract could be absorbed. In fact, it has been established that charcoal has been used as antidote for substance poisoning including alkaloid (Katona et al., 1987).

Thus, to remove chlorophyll in this work, the ethanolic extracts were subjected to liquid-liquid extraction by adding hexane in the ratio of 5:6 $(\mathrm{v} / \mathrm{v})$ for extract:hexane. The mixture was shaken vigorously and the phases were allowed to separate. The bottom layer that contained flavonoids was recovered to proceed with the flavonoids analysis. A method performed by Sólyom et al. (2014) was referred where $1 \mathrm{~mL}$ of $C$. nutans extract was taken into a test tube and mixed with $300 \mu \mathrm{L}$ of $5 \%$ sodium nitrite solution $\left(\mathrm{NaNO}_{2}\right)$. After $5 \mathrm{~min}, 500 \mu \mathrm{L}$ of $2 \%$ aluminum chloride solution $\left(\mathrm{AlCl}_{3}\right)$ was added into the test tube followed by the addition of sodium hydroxide $(\mathrm{NaOH})$ after 6 min of equilibration. The mixture was thoroughly mixed during $10 \mathrm{~min}$ and diluted with $10 \mathrm{~mL}$ with Milli-Q water. The absorbance of the reaction mixture was then measured at $510 \mathrm{~nm}$ by UV-vis spectrophotometer against a blank which was prepared with the same procedure as samples. The total flavonoids content was calculated from a standard calibration curve (100-500 $\mathrm{mg} / \mathrm{L}$ ) and the results were expressed as quercetin equivalent, mg quercetin $(\mathrm{QE}) / \mathrm{g}$ dried material (DM).

\subsection{Total phytosterols content}

The total phytosterols content in C. nutans extracts was determined according to the method described by Araújo et al. (2013) with slight modifications. Prior to the analysis, the extracts were subjected to alkaline saponification to cleave the acetal bond between the phytosterol and the carbohydrate moiety (Liu et al., 2007). In this work, a direct saponification was performed as done by Xiao et al. (2013) with slight modification, under microwave irradiation of $20 \mathrm{~mL}$ of $1.5 \mathrm{~mol} / \mathrm{L}$ ethanolic of $\mathrm{KOH}$ at $300 \mathrm{~W}$ within $15 \mathrm{~s}$. Unsaponifiable matter was removed by two consecutive liquid-liquid extractions with hexane $(5 \mathrm{~mL})$ and washed with $0.5 \mathrm{M} \mathrm{KOH}(2 \times 5 \mathrm{~mL})$ and $2 \times 5 \mathrm{~mL}$ of Milli-Q water. Hexane was vaporized and the extract residue was dissolved in $5 \mathrm{~mL}$ of chloroform prior to the analysis. For SFE extract, the oil extracts $(3 \mathrm{~mL})$ were saponified with $3 \mathrm{~mL}$ of $2 \mathrm{~mol} / \mathrm{L} \mathrm{KOH}$ ethanolic solution at $80^{\circ} \mathrm{C}$ for $1 \mathrm{~h}$. After the saponification, the solution was cooled down to room temperature and $2 \mathrm{~mL}$ of Milli-Q water were added to homogenize the solution. The unsaponifiable matter was separated from the extract by liquid-liquid extraction as previously described and dissolved in $5 \mathrm{~mL}$ of chloroform. Prior to the phytosterols detection, about $2 \mathrm{~mL}$ of the Liebermann-Burchard (LB) reagent was added to $5 \mathrm{~mL}$ of chloroform sample extracts and volume was increased with chloroform to $10 \mathrm{~mL}$. After $5 \mathrm{~min}$ of reaction time, the absorbance of the samples was measured by UV-vis spectrophotometer at $625 \mathrm{~nm}$ against a blank sample. The Liebermann-Burchard (LB) reagent was prepared by adding about $50 \mathrm{~mL}$ of acetic anhydride into an amber glass vial and kept in an ice bath. After $30 \mathrm{~min}, 5 \mathrm{~mL}$ of sulphuric acid was added to the acetic anhydride. Results of the total phytosterols measurements were determined by referring to a standard calibration curve of $\beta$ sitosterol (20-100 mg/L) and expressed as mg of $\beta$-sitosterol (BS)/g dried material (DM).

\subsection{Ultra-performance liquid chromatography (UPLC) analysis}

Ultra-performance liquid chromatography (UPLC) analyzes were carried out using a waters Acquity UPLC system (Waters Corporation, Milford, MA, USA). Samples were separated on reverse phase in Acquity UPLC BEH C18 $(1.7 \mu \mathrm{m} \times 2.1 \times 50 \mathrm{~mm})$ column with mobile phases of $0.1 \%$ formic acid in Milli-Q water and $0.1 \%$ formic acid in acetonitrile in a gradient elution mode. The addition of formic acid significantly enhances the efficiency of ionization (Nováková et al., 2010). The injection volume was $1 \mu \mathrm{L}$ and the oven temperature was maintained at $25^{\circ} \mathrm{C}$. For the ESI/QTOF/MS, UPLC was coupled with to a quadrupole-time-of-flight micro-TOF-Q (Bruker Daltonik GmbH, Bremen, Germany), an orthogonal accelerated QTOF mass spectrometer, equipped with an ESI. A negative ion mode was set with spectra acquired over a mass range from $m / z$ 50 to 1300 . The optimum parameters of the ESI/MS were found to be: capillary voltage, $+2.5 \mathrm{kV}$; drying gas temperature, $200^{\circ} \mathrm{C}$; drying gas flow, $8.0 \mathrm{~L} / \mathrm{min}$; nebulising gas pressure, 2.0; collision RF, $300 \mathrm{Vpp}$; transfer time $120.0 \mu \mathrm{s}$; and pre-pulse storage, $8.0 \mu \mathrm{s}$. An automation of MS was set at collision energy as $-10 \mathrm{eV}$. The mass data was processed by Data Analysis 4.1 software (Bruker Daltonics, Bermen, Germany), that provided a list of possible elemental formulae using the generate molecular formula editor.

\subsection{Statistical analysis}

All analyzes were done in triplicate. Results are reported as mean values and standard deviations. One-way analysis of variance (ANOVA) tests were performed in Microsoft Excel 2012 to analyze 
Table 1

Phytocomponents identified by GC/MS in C. nutans extracts obtained by microwave assisted extraction (MAE), supercritical fluid extraction (SFE) and Soxhlet extraction.

\begin{tabular}{|c|c|c|c|c|c|}
\hline \multirow[t]{2}{*}{ Compounds } & \multicolumn{3}{|l|}{ Peak area (\%) } & \multirow[t]{2}{*}{ Nature of compound } & \multirow[t]{2}{*}{ Biological activity } \\
\hline & $\operatorname{MAE}(86 \% \mathrm{v} / \mathrm{v})$ & $\operatorname{SFE}\left(350 \mathrm{bar}, 60^{\circ} \mathrm{C}\right)$ & Soxhlet (abs ethanol) & & \\
\hline Neophytadiene & 13.44 & 2.73 & - & Diterpene & $\begin{array}{l}\text { Anti-microbial, } \\
\text { anti-flammatory }\end{array}$ \\
\hline Iron & 3.00 & - & - & Metal ions & $\begin{array}{l}\text { Haemoglobin formation agent, } \\
\text { maintain immune function }\end{array}$ \\
\hline 7,9-Dodecadien-1-ol & 4.25 & - & - & Alcohol & NA \\
\hline Myristic acid & - & 2.12 & - & Fatty acid & Flavouring, skin care \\
\hline Palmitic acid acid, methyl ester & 3.09 & - & 5.91 & Fatty acid & Antibacterial, antifungal \\
\hline Palmitic acid & 29.23 & 43.49 & 12.13 & Fatty acid & Antibacterial, antifungal \\
\hline Benzenethanol & 3.74 & - & - & Alcohol & NA \\
\hline Phytol & 34.99 & 11.34 & 75.42 & Diterpene & $\begin{array}{l}\text { Antiradical, antimicrobial, } \\
\text { anti-cancer }\end{array}$ \\
\hline Squalene & - & 5.58 & - & Triterpene & $\begin{array}{l}\text { Anticancer, antimicrobial, } \\
\text { antioxidant, chemo preventive, } \\
\text { pesticide, anti-tumour, } \\
\text { sunscreen }\end{array}$ \\
\hline Stearic acid, methyl ester & 4.53 & 17.43 & - & Fatty acid & Antibacterial, antifungal \\
\hline Margaric acid, ethyl ester & - & 0.50 & 6.54 & Fatty acid & NA \\
\hline Lupeol & 3.73 & - & - & Triterpene & $\begin{array}{l}\text { Antiprotozoal, antimicrobial, } \\
\text { anti-inflammatory, antitumor } \\
\text { and chemopreventive } \\
\text { properties }\end{array}$ \\
\hline Linoleic acid, ethyl ester & - & 15.77 & - & Fatty acid & Antibacterial, antifungal \\
\hline Linolenic acid, methyl ester & - & 1.04 & - & Fatty acid & $\begin{array}{l}\text { Anti-microbial, } \\
\text { anti-inflammatory }\end{array}$ \\
\hline
\end{tabular}

the effect of solvent concentration, determining the cases where the difference between individual means was statistically significant, with $p<0.05$.

\section{Results and discussion}

The extraction yields obtained by MAE, SFE and Soxhlet methods were compared to each other by considering solvent consumption and extraction time as presented in Fig. 2. In this figure, the extraction yield is expressed as g/g dry material while the moisture content was $11.77 \mathrm{wt} \%$ in dry weight basis. As it can be seen in Fig. 2, the lowest extraction yield was obtained by SFE method, with $3.19 \mathrm{wt} \%$ on dry basis after $120 \mathrm{~min}$ of extraction at 350 bar and $60^{\circ} \mathrm{C}$, while the highest yield of $21.28 \mathrm{wt} \%$ was obtained by Soxhlet extraction, and an intermediate yield of $17.39 \mathrm{wt} \%$ was achieved by MAE method. The low yield obtained by SFE is probably due to the non-polar nature of the carbon dioxide solvent that is unfavorable for extracting the abundant polar compounds present in C. nutans oil, such as chlorophyll and polyphenols (see Section 3.3). Besides, a slower extraction rate in the course of extraction (shown in Fig. 5 in Section 3.6) indicated that the oil extraction was controlled by mass transfer resistance as the solutes were strongly bound with the plant matrix. As consequences, the fluid-phase concentration became much lower than the solubility (Sovová, 2005) and prolonged the extraction time needed to achieve asymptotic yield. The solubility of $C$. nutans oil was as low as $0.242 \mathrm{mg}$ oil $/ \mathrm{g} \mathrm{CO}_{2}$. A relatively high amount of carbon dioxide of $315 \mathrm{~g}$ solvent $/ \mathrm{g}$ feed compressed for 120 min needed in order to achieve an extraction yield of only $3.19 \mathrm{wt} \%$, indicates that the supercritical extraction for the $C$. nutans was an unfavorable method considering the economic feasibility of the process.

On the other hand, the highest yield achieved by Soxhlet extraction can be explained by application of the high temperature $\left(82^{\circ} \mathrm{C}\right)$ during a longer period ( $\left.480 \mathrm{~min}\right)$ compared to MAE which the temperature was $70^{\circ} \mathrm{C}$ at $300 \mathrm{~W}$ during $15 \mathrm{~s}$ and completed with conventional extraction at $40^{\circ} \mathrm{C}$ in $80 \mathrm{~min}$. The elevated temperature contributed to the process efficiency as the saturation concentration was increased improving the compounds extractability (Aspé and Fernández, 2011). Besides, the different concentration of the ethanol solutions used for the extraction by Soxhlet (100\% ethanol) and MAE ( $86 \% \mathrm{v} / \mathrm{v})$ may also contribute to the lesser yield achieved by MAE. However, considering the factor of solvent consumption where MAE requires only $13 \mathrm{~g}$ solvent $/ \mathrm{g}$ feed instead of $21 \mathrm{~g}$ solvent/g feed in Soxhlet the extraction time which is significantly shorter for MAE (15s) than for Soxhlet (480 min) and the energy consumption, microwave treatment appears as a favorable method for the $C$. nutans extraction.

\subsection{Phytocompounds identification}

GC/MS analyzes were performed on the ethanolic extracts from MAE and Soxhlet as well as on the SFE extract. The various phytochemical compounds identified that can contribute to the bioactivity of $C$. nutans are presented in Table 1 . The analysis on the extracts revealed that $C$. nutans extract comprises diterpene, triterpene, fatty acids and other bioactive compounds. Most of the compounds identified can exhibit several biological activities, such as antibacterial, anti-inflammatory and antioxidants, as for example phytol, squalene and lupel. Phytol was found as the major compound in the MAE and Soxhlet whilst palmitic acid was the major component in the SFE extract. These compounds have been claimed to have antiradical, anti-microbial, anti-inflammatory, antitumor and chemopreventive properties (Pejin et al., 2014; Saleem, 2009). Other bioactive compounds, such as neophytadiene have been identified as strong bactericidal and anti fungal terpenoids compounds (Carretero et al., 2008; Mendiola et al.,

Table 2

Chlorophyll content in C. nutans extracts.

\begin{tabular}{|c|c|c|c|}
\hline Solvent & Chlorophyll a (g/g sample) & Chlorophyll b (g/g sample) & Total chlorophyll(g/g DM) \\
\hline Ethanol & 0.38 & 0.77 & 1.30 \\
\hline Acetone & 0.48 & 0.45 & 1.06 \\
\hline
\end{tabular}




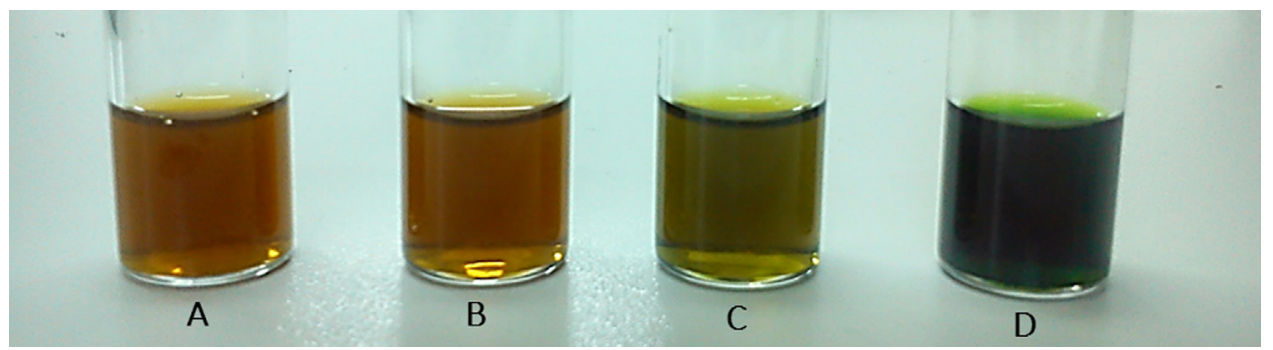

Fig. 3. Colour of extracts at different concentration of ethanol. (A) $44 \% \mathrm{v} / \mathrm{v}$, (B) $50 \% \mathrm{v} / \mathrm{v}$ (C) $65 \%$ and (D) $86 \% \mathrm{v} / \mathrm{v}$.

2008). Moreover, fatty acids, such as palmitic acid, linoleic acid and linolenic acid have also been identified to act as antibacterial and antifungal agents against Escherichia coli, Staphylococcus aureus and Bacillus subtilis (Agoramoorthy et al., 2007).

In addition, SFE extract included interesting compounds based on the triterpene group, as squalene and several long fatty acids that were not found in MAE or Soxhlet extracts. Squalene has been reported to exhibit anti-cancer, antioxidant, chemopreventive, anti-tumor (Ezhilan and Neelamegam, 2012), anti-cancerogenic and reducing serum cholesterol levels (Rao et al., 1998). These results show that the type of compounds present in extracts is highly dependent on the nature of solvent and on the technique of extraction employed. Due to the characteristics of solvents employed, MAE extraction enabled obtaining several minority polar compounds, while non-polar fatty compounds mainly were obtained by SFE. In contrast, Soxhlet extracts did not include any of these minority compounds. This can be due to a partial degradation of these compounds during the long processing times at high temperature required for Soxhlet extraction.

\subsection{Chlorophyll content}

Sakdarat et al. (2009) identified three chlorophyl derivatives related to the structures of chlorophyll a and b, namely 13(2)-hydroxy-(13(2)-R)-phaeophytin b, 13(2)-hydroxy-(13(2)$S)$-phaeophytin a and 13(2)-hydroxy-(13(2)-R)-phaeophytin a. These compounds were investigated by these authors and exhibited anti-herpes simplex activity. It has been demonstrated by several researchers that the chlorophyll pigments show a diverse range of biological properties, such as antioxidant, antimutagenic activities, chemopreventive action and induction of apoptosis activity in cancer cells (Dashwood, 1997; Ferruzzi and Blakeslee, 2007). Therefore, it is considered that the the presence of chlorophyll in the extract also contribute to the medicinal properties of C. nutans.
Total amounts of chlorophyll a and b determined in this work are shown in Table 2. Results showed a high concentration of chlorophyll in the $C$. nutans leaves and stems. On the other hand, as it can be observed from Table 2, ethanol extractions attained higher chlorophyll content compared to acetone extractions. Even though, acetone has been used for many decades for chlorophyll determination as it could give a very sharp chlorophyll absorption peak, it is a poor extracting solvent of chlorophyll from many vascular plants (Ritchie, 2008). In addition, very low chlorophyll contents were obtained by extraction with a $50 \% \mathrm{v} / \mathrm{v}$ ethanol/water mixture, and the highest amounts of chlorophyll were obtained by extraction with a $86 \% \mathrm{v} / \mathrm{v}$ ethanol-acidified water mixture.

It is interesting to note that different color of extracts was obtained at different ethanol concentration (see Fig. 3). It was observed that the higher ethanol concentration the greener the color of extract. This is possibly due to the higher solubility of chlorophyll at high ethanol concentration.

\subsection{Total phenols content (TPC)}

The total phenols content of sample extracts are presented in Table 3. In general, a higher TPC was obtained by ethanol extraction assisted by microwave irridiation (MAE) than by supercritical fluid extraction (SFE). This phenomenon can be explained by the nature of the solvent used in the extraction, as the non-polar nature of supercritical carbon dioxide makes it less suitable than ethanol-water mixtures for the extraction of polar polyphenol compounds (Brahmi et al., 2012; Le Floch et al., 1998). Phenolic compounds comprise one or more hydroxyl groups (polar fragments) and phenyl groups or aromatic rings (non-polar fragments). These compounds are often found in plants as esters or glycosides rather than as free molecules (Queimada et al., 2009). With this structure, they can form a hydrogen bond with water molecules as well as with an electronegative oxygen of ethanol and vice versa (Galanakis et al., 2013), making them soluble in polar solvents.

Table 3

Total phenols content (TPC) and total flavonoids (TF) obtained with different methods of extraction.

\begin{tabular}{|c|c|c|c|}
\hline Method & Ethanol concentration $(\% \mathrm{v} / \mathrm{v})$ & TPC (mg GAE/g DM) & TF (mg quercetin/g DM) \\
\hline \multirow[t]{4}{*}{ MAE } & 44 & $11.09 \pm 0.28$ & $4.24 \pm 0.12$ \\
\hline & 50 & $11.30 \pm 0.39$ & $4.66 \pm 0.20$ \\
\hline & 65 & $9.31 \pm 0.18$ & $4.54 \pm 0.20$ \\
\hline & 86 & $5.74 \pm 0.29$ & $3.41 \pm 0.76$ \\
\hline \multirow[t]{4}{*}{${ }^{\mathrm{a}} \mathrm{P}-\mathrm{MAE}$} & 44 & $13.23 \pm 0.40$ & $5.23 \pm 0.40$ \\
\hline & 50 & $14.56 \pm 0.77$ & $5.29 \pm 0.30$ \\
\hline & 65 & $12.89 \pm 0.90$ & $5.07 \pm 0.56$ \\
\hline & 86 & $8.88 \pm 0.85$ & $2.71 \pm 0.47$ \\
\hline Control (MAE) & 44 & $8.89 \pm 0.46$ & $4.27 \pm 0.22$ \\
\hline Soxhlet & Absolute & $7.95 \pm 0.21$ & $3.04 \pm 0.02$ \\
\hline SFE & No ethanol $\mathrm{CO}_{2} 350 \mathrm{bar}, 60^{\circ} \mathrm{C}$ & $7.01 \pm 0.15$ & $5.88 \pm 0.22$ \\
\hline
\end{tabular}

Values are mean \pm S.D of triplicate experiments.

a At pressure $=2.7$ bar. 


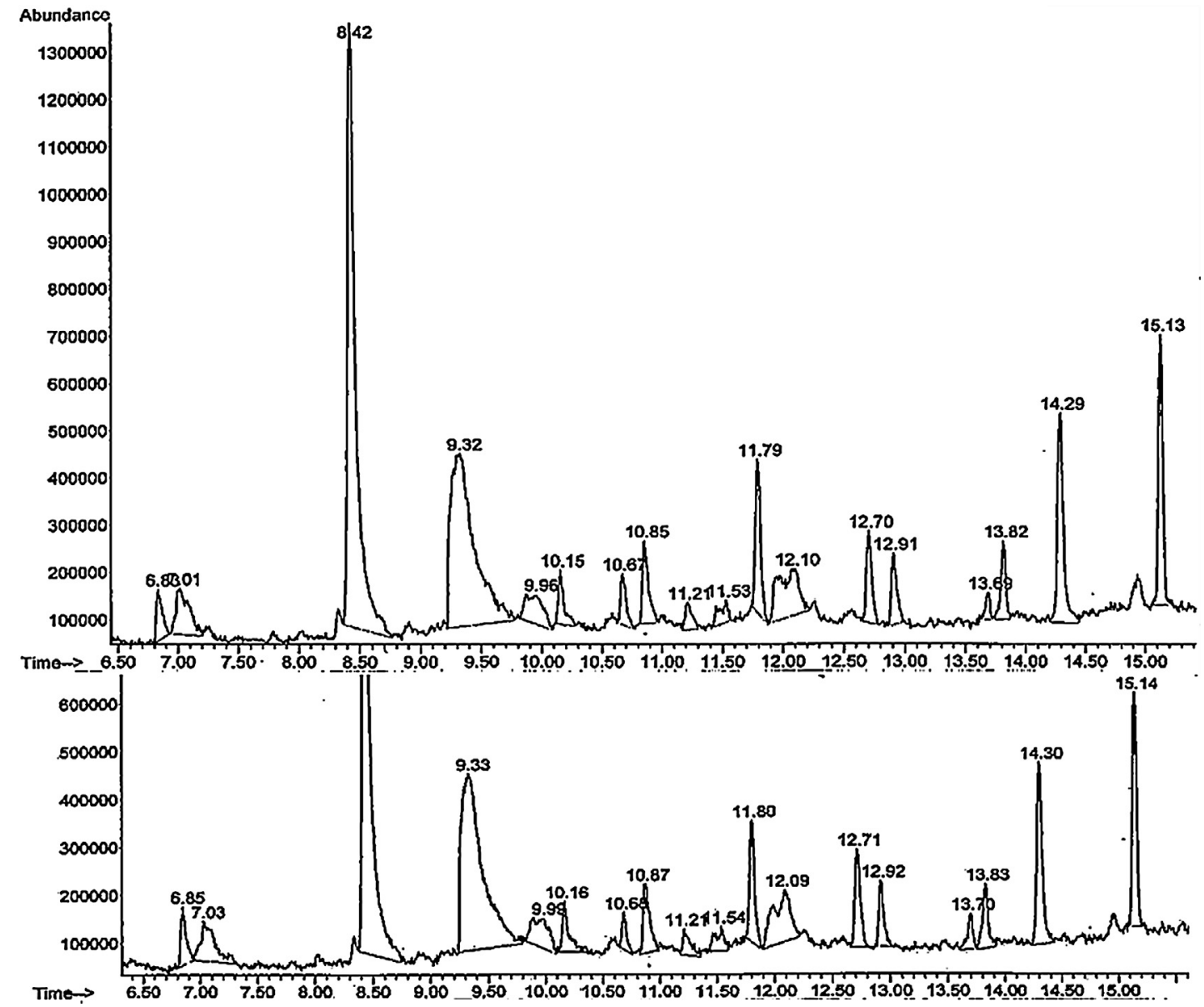

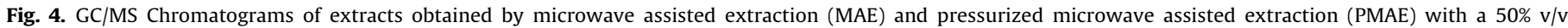
ethanol/water solvent.

In our method, an additional amount of solvent $(6 \mathrm{~mL})$ was added after the MAE irridation to increase the compounds solubility into the solvent and minimize the mass transfer limitation of compounds. The solvent amount was determined by the solventto-feed-ratio and the desired final volume of solvent. Indeed, from preliminary experiments, it was found that by adding the solvent after the MAE enhanced the total phenols content from 9.19 to
$11.09 \mathrm{mg} \mathrm{GAE} / \mathrm{g} \mathrm{DM}$ at $44 \% \mathrm{v} / \mathrm{v}$ ethanol (not shown in this work). Hence, this method improved the extractability of polyphenols from sample matrix into extracting solvent.

The proportion between solvents in water-ethanol mixtures must be set depending on the specific compounds targeted. At low concentration of ethanol (i.e., $50 \% \mathrm{v} / \mathrm{v}$ ), a higher amount of polyphenols can be extracted, whereas less polyphenols can obtained

Table 4

GC/MS phytochemical compounds identified in extracts obtained by MAE and P-MAE with 50\% v/v ethanol-water mixtures.

\begin{tabular}{|c|c|c|c|c|c|c|}
\hline \multirow[t]{2}{*}{ No. } & \multirow[t]{2}{*}{ Compound } & \multirow[t]{2}{*}{$\mathrm{RT}(\min )$} & \multicolumn{2}{|c|}{ Peak area (\%) } & \multirow[t]{2}{*}{ Nature of compound } & \multirow[t]{2}{*}{ Activity/uses } \\
\hline & & & MAE50 & P-MAE50 & & \\
\hline 1 & 2-Butanol & 6.85 & 1.97 & 1.98 & Carboxylic acid & Antimicrobial \\
\hline 2 & Butanamide & 7.02 & 3.63 & 3.66 & Amide & Antimicrobial \\
\hline 3 & 2-cyclopenten-1-one, 2-hydroxy & 8.43 & 27.64 & 28.00 & Cyclic ketone & Fragrance \\
\hline 4 & Glycine & 9.33 & 22.05 & 22.24 & Amino acid & $\mathrm{NA}$ \\
\hline 5 & Pentanal & 9.99 & 3.18 & 3.21 & Aldehyde & Antimicrobial \\
\hline 6 & Isoveraldehyde & 10.16 & 2.15 & 2.11 & Aldehyde & Food flavouring \\
\hline 7 & Dimethyl trisulfide & 10.68 & 1.05 & 1.09 & Organosulfur & Antimicrobial \\
\hline 8 & Thiophene & 10.87 & 2.94 & 2.82 & Heterocyclic & Antimicrobial \\
\hline 9 & Succinic acid & 11.21 & 1.17 & 1.25 & Organic acid & Antimicrobial \\
\hline 10 & Glycolic acid & 11.54 & 1.30 & 1.44 & $\alpha$-Hydroxy acid & Food preservative, skin care agent \\
\hline 11 & Oxazolidine & 11.80 & 3.87 & 3.99 & Nitrogen compound & Antimicrobial \\
\hline 12 & Thiophene & 12.09 & 5.56 & 5.74 & Heterocyclic & Antimicrobial \\
\hline 13 & 9-Azabicyclo (6.1.0) non-4-4en-9-amine & 12.71 & 3.51 & 2.77 & Azo compound & NA \\
\hline 14 & 4-Vinyl-2-methoxy-phenol & 12.92 & 2.03 & 2.20 & Phenol & Antioxidant \\
\hline 15 & Phenol,2,6-dimethoxy & 13.70 & 1.20 & 1.31 & Phenol & Antioxidant \\
\hline 16 & 4H-Pyran-4-one,2,3-dihydro-3,5-dihydroxy-6-methyl & 13.83 & 2.33 & 2.51 & Flavonoid fraction & Antimicrobial, anti-inflammatory \\
\hline 17 & Glycerine & 14.30 & 6.46 & 6.95 & Alcohol & Antimicrobial, preservative \\
\hline 18 & 4-Vinylphenol & 15.14 & 6.36 & 6.73 & Phenol & Antioxidant \\
\hline
\end{tabular}




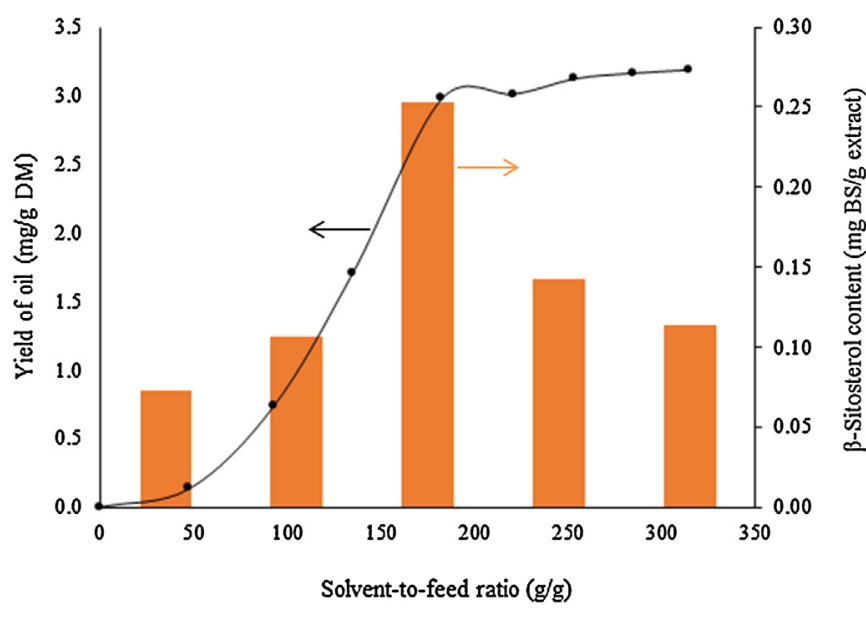

Fig. 5. Oil (line) and $\beta$-sitosterol (columns) yields obtained by Supercritical Fluid Extraction as a function of the solvent-to-feed ratio.

at high ethanol concentration due to the solubility competition between phenolics compounds and chlorophyll that is governed by polarity factor and also might be a thermodynamic property i.e., activity coefficient. Galanakis et al. (2013) explained that a tedency of phenols to be transferred, solubilized and diffused was dependent on activity coefficient, as with smaller activity coefficients the solubility was higher and vice versa.

On the other hand, the maximum contents of polyphenols were obtained with ethanol/water mixtures in a $50 \% \mathrm{v} / \mathrm{v}$ proportion, with lower contents (with a statistically significant difference with $p<0.05$ ) when the proportion of ethanol was either increased or decreased. This result agrees with the findings by Spigno et al. (2007) who found that the phenols concentration decreased when the proportion of ethanol in the mixture was increased beyond $50 \% \mathrm{v} / \mathrm{v}$. This behavior is due to the molecular structure of phenols which comprises both polar and non-polar fragments, limiting its solubility in ethanol-water mixture depending on the proportions between the two solvents. Moreover, the lower phenols content observed at $44 \% \mathrm{v} / \mathrm{v}$ of ethanol can also be due to the co-extraction of other compounds which decrease the phenols content in the extract. Spigno et al. (2007) mentioned that the addition of water to ethanol improved the extraction rate, but excessive water in solvent mixture could reduce the phenols content as other contaminants were also extracted.

As previously indicated, the low TPC content in SFE extracts can be expected due to the non-polar nature of supercritical carbon dioxide. This result is in agreement with the observations of Rombaut et al. (2014) who performed an extraction of polyphenols from grape seed by supercritical cabon dioxide without the aid of any co-solvent also found a very low extracion yield of polyphenols i.e., between 0.061 and $0.067 \mathrm{~g}$ extract/g dry material after $120 \mathrm{~min}$ at $53.8 \mathrm{MPa}$ and $104^{\circ} \mathrm{C}$. A higher TPC content is expected if a cosolvent, such as ethanol is employed in the SFE process due to the increasing solubilities of high molecular weight phenolics (Sanjaya et al., 2014), as reported by several researchers (Kazan et al., 2014). However, the use of organic co-solvents in SFE processes consideraby complicates the purification and recycling of carbon dioxide, increasing costs, and it is rarely used in commercial SFE plants.

Furthermore, the TPC of Soxhlet extract was also lower compared to the contents in MAE and P-MAE extracts, even though the total extraction yield obtained by Soxhlet was higher. This is probably due to the absence of water in the ethanol solvent used in Soxhlet, leading to a lower solubility of the polyphenols in the solvent.

\subsection{Flavonoids content}

Flavonoids are secondary metabolites of plants with polyphenolic structure and have several pharmocological activities, such as anti-cancer, antioxidant, anti-viral and anti-inflammatory. In this work, the trend of total flavonoids content in extracts was similar as the trend of polyophenol content described in the previous section. The total flavonoids content obtained by MAE showed a maximum value of. $4.66 \pm 0.20 \mathrm{mg}$ quercetin $/ \mathrm{g}$ DM at $50 \%$ $\mathrm{v} / \mathrm{v}$ when the concentration of ethanol was increased from $44 \%$ $\mathrm{v} / \mathrm{v}$ to $50 \% \mathrm{v} / \mathrm{v}$. However, a further increase in the ethanol concentration to $86 \% \mathrm{v} / \mathrm{v}$ insignificantly $(p>0.05)$ reduced the total flavonoids content to $3.41 \pm 0.76 \mathrm{mg}$ quercetin $/ \mathrm{g}$ DM. The lowest flavanoids content obtained at $86 \% \mathrm{v} / \mathrm{v}$ of ethanol was probably due to the extraction of non-polar aglycone flavonoids by hexane during the pre-treatment of liquid-liquid extraction (LLE) to remove chlorophyll thereby leaves merely polar flavonoids (glycosides flavonoids) in the extracts (Mabry et al., 1970), thus, reduced the total amount of flavonoids content. Furthermore, it also might be due to the extraction competition between chlorophyll and flavonoids from the plant leaves as a function of ethanol concentration. Previously, flavonoids content in C.nutans has been reported by several reseachers, for example Ho et al. (2013) found $0.04 \pm 0.001 \mathrm{mg} \mathrm{QE} / \mathrm{g}$ of total flavonoids content after extracted $C$. nutans using methanol maceration for 3 days whilst and Tiew et al. (2014) discovered $0.21 \pm 0.005 \mathrm{mg} \mathrm{QE} / \mathrm{g}$ dry extract by using the same extraction procedure. Differences in values of the flavonoids might be due to different extraction method and solvent employed. In addition, a microwave pre-treatment could signficantly enhance the extractability of the polyphenols from the $C$. nutans plant. Moreover, the degradation of flavonoids during the extraction procedure can be an important factor, as flavonoids are labile compounds that can easily undergo degradation reactions in aqueous media. With respect to this, it is remarkable the high flavonoid content achieved by SFE (Table 3), even though flavonoids are polar compounds that are not easily extractable by $\mathrm{SC}-\mathrm{CO}_{2}$. This result is probably a consequence of a lower degradation of the compounds during SFE, as with this procedure a dry extract is obtained along the course of the extraction thus avoiding possible degradation reactions in aqueous media.

\subsection{MAE vs pressurised-MAE (P-MAE)}

In this work, an extraction assissted by microwave under pressure (P-MAE) at 2.7 bar was also carried out with same parameters as MAE experimens. The extracts were analyzed to determine the TPC and flavonoids, phytosterols content as well as polyphenols characterization by UPLC/MS. The results are shown in Tables 3-5, respectively. In general, the TPC and flavonoids content in the PMAE extracts were similar to the values obtained by MAE. The TPC value decreased from 13.23 to $8.88 \mathrm{mg}$ GAE/g DM significantly $(p<0.05)$ when ethanol concentration was reduced from 44 to $86 \% \mathrm{v} / \mathrm{v}$. Pressurised-MAE (P-MAE) enhanced the extractability of the polyphenols about $2-4 \mathrm{mg}$ GAE/g DM of the TPC in MAE extracts at different ethanol concentrations. The increasing temperature produced by a higher pressure could have caused damage to the cell walls of the plant, stimulating compounds releasing and enhancing its dissolution into the solvent. The high temperature achieved in P-MAE that is up to $108^{\circ} \mathrm{C}$ also contributed to the high extractability of the compounds from plant sample. This factor has further affected the flavonoids extraction when the its content was found to be much higher compared to the flavonoids content obtained by conventional MAE. The maximum value of flavonoids, i.e., $5.29 \pm 0.33 \mathrm{mg}$ quercetin/g DM, was observed at $50 \% \mathrm{v} / \mathrm{v}$ and the effect of a variation in ethanol concentration from 44 to $86 \% \mathrm{v} / \mathrm{v}$ on this amount was significant. Furthermore, as the 


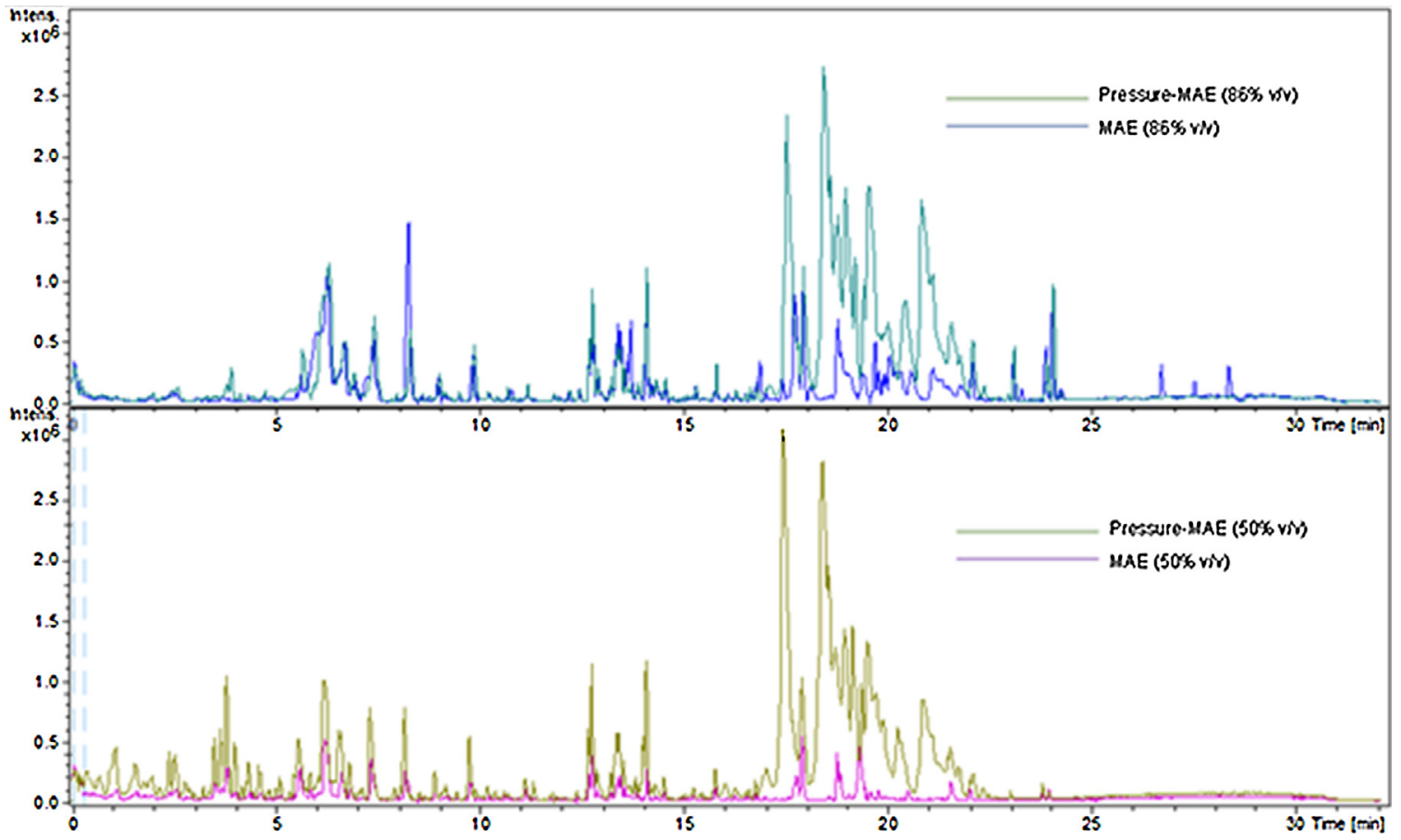

Fig. 6. UPLC QTOF ESI/MS chromatogram of extracts obtained by MAE and P-MAE at $86 \% \mathrm{v} / \mathrm{v}$ and $50 \% \mathrm{v} / \mathrm{v}$ of ethanol.

ethanol concentration was increased to $86 \% \mathrm{v} / \mathrm{v}$, the flavonoids content decreased to the lowest amount of $2.71 \pm 0.50 \mathrm{mg}$ quercetin $/ \mathrm{g}$ DM. It is important to note that the application of P-MAE did not improve any major difference in the variety of compounds extracted compared to MAE. As it can be seen from Fig. 4 and Table 4 , both extracts of MAE50 and P-MAE50 comprised similar phytochemical compounds. However, the extraction yields obtained by P-MAE were slightly higher than the yields obtained by MAE. This result suggested that MAE treatment is sufficient to improve the extractability of compounds from the plant material. Morevover, the P-MAE solely enhanced the extraction yield rather than the variety of compounds extracted.

In MAE and P-MAE process, $50 \% \mathrm{v} / \mathrm{v}$ of ethanol was found as the optimum concentration for the $C$. nutans extraction in producing the highest TPC and TF. Even though the flavonoids content was increased with ethanol, small differences were found. Moreover, ethanol with more than $50 \% \mathrm{v} / \mathrm{v}$ can caused local mucosal lesions through dehydration and albumin precipitation (Europe, 1994) meanwhile ethanol concentration in excess of $60 \% \mathrm{v} / \mathrm{v}$ could be toxic for short-term and prolonged use of ethanol-containing herbal medicinal products (European Medicines Agency, 2010). There is also another study by Chung et al. (2002) concerning the ethanol concentration for human consumption, who studied the antioxidant activity and the safety of $50 \%$ ethanolic extract from red bean fermented. They claimed that the $50 \%$ ethanolic extract was found to be safe in genotoxicity as no mutagenicity or toxicity effect was found on the tester strains. Genotoxicity is a phenomenon describing the property of chemical solvent can cause a mutation of cells which lead to cancer. Thus, from the economic, safety and polyphenols extractability, point of view, it is suggested to use $50 \%$ $\mathrm{v} / \mathrm{v}$ of ethanol as an optimum concentration to extract total phenols compounds from $C$. nutans sample.

\subsection{Total phytosterols and $\beta$-sitosterol}

Phytosterols are plant sterols members of the 'terpene' family of natural products and classified as low polarity or non-polar compounds. Their nutraceutical activities include anti-inflammatory, anti-bacterial, anti-ulcerative and anti-tumor properties (Beveridge et al., 2002; Llaverias et al., 2013). The most abundant phytosterol components found in plant oil are $\beta$-sitosterol, stigmasterols and campesterol. In this work, analyzes of total phytosterol (TP) and $\beta$-sitosterol by UV-vis

Table 5

Total phytosterol (TP) content and $\beta$-sitosterol (BS) yield obtained with methods of extraction.

\begin{tabular}{|c|c|c|c|}
\hline Method & Ethanol concentration $(\% \mathrm{v} / \mathrm{v})$ & TP (mg BS/g DM) & $\mathrm{BS}(\mathrm{mg} / \mathrm{g} \mathrm{DM})$ \\
\hline \multirow[t]{3}{*}{ MAE } & 50 & $0.19 \pm 0.13$ & - \\
\hline & 65 & $0.41 \pm 0.20$ & $0.16 \pm 0.22$ \\
\hline & 86 & $0.70 \pm 0.10$ & $0.52 \pm 0.10$ \\
\hline \multirow[t]{3}{*}{ aP-MAE } & 50 & $0.35 \pm 0.12$ & - \\
\hline & 65 & $1.04 \pm 0.15$ & $0.45 \pm 0.20$ \\
\hline & 86 & $1.19 \pm 0.22$ & $0.65 \pm 0.14$ \\
\hline Control & 44 & - & - \\
\hline Soxhlet & Absolute & $0.47 \pm 0.20$ & $0.23 \pm 0.18$ \\
\hline SFE & 350 bar, $60^{\circ} \mathrm{C}$ & $1.35 \pm 0.12$ & $0.83 \pm 0.10$ \\
\hline MAE-KOH & $1.5 \mathrm{~mol} / \mathrm{L}$ ethanolic $\mathrm{KOH}$ & $2.36 \pm 0.15$ & $0.64 \pm 0.13$ \\
\hline Control-ethanolic $\mathrm{KOH}$ & & $0.88 \pm 0.14$ & $0.40 \pm 0.10$ \\
\hline
\end{tabular}

a At pressure $=2.7$ bar 
Table 6

Characterization of phenolic compounds from ethanolic extracts $(86 \% \mathrm{v} / \mathrm{v})$.

\begin{tabular}{|c|c|c|c|c|c|}
\hline Peak & ${ }^{\mathrm{a}} \mathrm{Rt}$ & Compound & Class & {$[\mathrm{M}-\mathrm{H}]^{-}$} & Major fragments $(\mathrm{m} / \mathrm{z})$ \\
\hline 1,3 & 1.10 & Kaempferol-7-neohesperidoside & Flavones & 594 & 593 \\
\hline 4 & 6.02 & Isoschaftoside & C-glycosylated flavone & 563 & $353,383,443$ \\
\hline 10 & 9.90 & Unknown flavones & Flavones & 613 & 225,243 \\
\hline 12 & 12.7 & Isoorientin & Flavones (luteolin glucoside) & 448 & 327,357 \\
\hline 17,20 & 16.6 & Vitexin & C-Glycosylated flavone & 432 & 283,311 \\
\hline 24,26 & 19.3 & 3',7-Dimethoxy-3-hydroxyflavone & Flavones & 298 & 297 \\
\hline
\end{tabular}

a $\mathrm{Rt}=$ retention time.

spectrophotometry and HPLC respectively were done to quantify the compounds in $C$. nutans extract.

Results are shown in Table 5. In general, by MAE and PMA extraction, phytosterols content was found to increase with a decreasing proportion of water in the solvent mixture, in agreement with the non-polar nature of these compounds. Results showed that MAE pretreatment yielded higher TP and $\beta$-sitosterol content than Soxhlet extraction when the proportion of ethanol in the solvent mixture was higher than $65 \% \mathrm{v} / \mathrm{v}$. It is also remarkable that in the control experiment performed by conventional hot water extraction without MAE treatment, no phytosterols were observed in the extract. As shown in Table 5, certain phytosterol content was observed in the control hot water extraction without microwave irradiation performed with addition of $\mathrm{KOH}$ as saponification reagent, using $20 \mathrm{~mL}$ of $1.5 \mathrm{~mol} / \mathrm{L}$ ethanolic of $\mathrm{KOH}$ at $40^{\circ} \mathrm{C}$ for $80 \mathrm{~min}$, but the TP and $\beta$-sitosterol content obtained by MAE were much higher. Therefore, irradiation of microwave toward the sample materials improved the extraction efficiency and reduced the extraction time. Furthermore, by applying a direct saponification with the aid of MAE the time consuming sample preparation can be simplified, minimizing the steps of the experimental procedure.

Analyzing the results obtained by SFE, as presented in Table $5 \mathrm{a}$ remarkable content of TP and $\beta$-sitosterol, of 1.35 and $0.83 \mathrm{mg} \mathrm{BS} / \mathrm{g}$ DM, respectively was obtained, that was higher than the concentrations showed by MAE or Soxhlet methods. This behavior can be explained by the similar polarity between phytosterol and carbon dioxide that enhanced the extraction efficiency by SFE. Moreover, the higher temperature applied in Soxhlet extraction probably caused the degradation of $\beta$-sitosterol and resulted in a lower phytosterols concentration. Sajfrtová et al. (2010) stated that it was also possible that atmospheric oxygen degraded and reduced the $\beta$-sitosterol content in the oil extracted by Soxhlet method.

The effect of solvent-to-feed ratio on the extraction yield of $\beta$-sitosterol by SFE at 350 bar and $60^{\circ} \mathrm{C}$ is shown in Fig. 5 . As the solvent-to-feed ratio was increased, the yield of $\beta$-sitosterol increased and passed through a maximum before dropping as the consumption of $\mathrm{CO}_{2}$ per mass of raw material was further increased. Initially, the concentration of $\beta$-sitosterol was low and then slowly increased as the time of extraction prolonged, and the maximum of $\beta$-sitosterol was obtained at the third fraction of the extraction course. High amount of $\beta$-sitosterol in the middle of the extraction fractions is probably due to the low solubility of the other compounds (triglycerides or fatty acids) in $\mathrm{CO}_{2}$ during that time then in turn offer an advantage to the $\beta$-sitosterol to dissolve in $\mathrm{SC}-\mathrm{CO}_{2}$. However, this behavior is in contradiction with some previous works. For example, de Arevalo (2008), reported that the highest concentration of $\beta$-sitosterol from soybean distillate waste was found at the first fraction of the extraction at pressure 200 and $300 \mathrm{bar}, 80^{\circ} \mathrm{C}$, claiming that the highest concentration of the compound obtained was due to the low solubility of other compounds in $\mathrm{CO}_{2}$ at the initial part of the extraction course. Nevertheless, differences in the extraction $\beta$-sitosterol might be due to different structure and chemical composition of plant materials (Sajfrtová et al., 2005).

\subsection{Characterization of metabolites in $\mathrm{C}$. nutans extract by UPLC-QTOF/MS}

Plant extracts generally contain primary metabolites, such as lipids, protein and carbohydrates whereas the secondary metabolites comprises alkaloids, terpenoids and phenolics. Phenolic compounds play an important role in cancer preventation and treatment by exhibiting diverse physiological properties such as antioxidant, anti-mutagenic, anti-imflammatory (Huang et al., 2010). The characterization of phenolic compounds from C. nutans extracts were done by UPLC-QTOF/MS as this technique provides high selectivity of detection and wide range of determination (Nováková et al., 2010). A negative ionization mode of MS data was used in this work since polyphenols contain one or more hydroxyl and/or carboxylic acid groups (Koolen et al., 2013).

In general, the UPLC analysis revealed that the MA extraction of $C$. nutans at different concentrations of ethanol yielded the same compounds, only with differences in their amounts when extracted with pressurised MAE. Similarly, the application of pressure in P-MAE experiments merely enhanced the extraction yield of phenolic compounds instead of improving the extractability of different compounds, as indicated also by GC/MS assays (Table 4). The UPLC-MS chromatograms of MAE and P-MAE extracts are shown in Fig. 6 whilst the characterized phenolic compounds are shown in Tables 6 and 7 for $86 \%$ and 50\% v/v ethanol, respectively. All the compounds are characterized by interpretation of their mass spectra from TOF-MS and based on the data provided in

Table 7

Characterization of phenolic compounds from ethanolic extracts $(50 \% \mathrm{v} / \mathrm{v})$.

\begin{tabular}{|c|c|c|c|c|c|}
\hline Peak & ${ }^{a} \mathrm{Rt}$ & Compound & Class & {$[\mathrm{M}-\mathrm{H}]^{-}$} & Major fragments $(\mathrm{m} / \mathrm{z})$ \\
\hline 1 & 1.10 & 2',6-Dihydroxyflavone & Flavone & 209 & $147,191,209$ \\
\hline 2 & 2.4 & $(+)-$ Catechin & Flavan-3-ol & 290 & $175,227,229,231$ \\
\hline 10 & $6.2-6.8$ & Isoschaftoside & C-glycosylated flavone & 563 & $353,383,443$ \\
\hline 13 & 7.0 & 7-Hydroxyflavone & Flavones & 193 & - \\
\hline 16 & 8.2 & Gallic acid & Phenolic acid & 169 & 125 \\
\hline $23-25$ & $12.5-13.3$ & Isoorientin & Flavones (luteolin glucoside) & 448 & 327,357 \\
\hline 27 & 15.8 & Vitexin & C-Glycosylated flavone & 432 & 283,311 \\
\hline 31 & 18.8 & Flavanone-7-O-glycoside & Flavones & 580 & 295,459 \\
\hline 32 & 19.1 & Unknown flavonoid & Flavonoid & 415 & - \\
\hline 34 & 19.7 & 3',7-Dimethoxy-3-hydroxyflavone & Flavones & 298 & 297 \\
\hline
\end{tabular}

a $\mathrm{Rt}=$ retention time. 
literature databases. The identification of the phenolic compounds by QTOF/MS was based on the deprotonated ions $[\mathrm{M}-\mathrm{H}]^{-}$and the MS/MS fragmentation released.

From ethanolic/water extracts of $86 \%$ and $50 \% \mathrm{v} / \mathrm{v}$, a wide range of metabolites groups were detected comprising phenolic compounds, terpene glycosides and oxygenated fatty acids. The identified phenolics belong to several classess of flavonoids, mainly phenolic acids, flavones, flavonol, flavanone, isoflavones, flavan3-ol, C-glycosylated flavone and anthocynidin. In both extracts of 50 and $86 \% \mathrm{v} / \mathrm{v}$, compounds of shaftoside, vitexin, isoorientin and 3',7-dimethoxy-3-hydroxyflavone has been identified. The identification of vitexin fragment at $m / z 311$ was also observed by Zhang et al. (2010) after the elimination of ions of $[\mathrm{M}-\mathrm{H}-120]^{-}$and $\left[\mathrm{M}-\mathrm{H}-\mathrm{C}_{4} \mathrm{H}_{8} \mathrm{O}_{4}\right]^{-}$and consistent with the characteristics ion of a $C$-glycosidic flavonoid (Li et al., 2006). The presence of vitexin in $C$. nutans extract has been reported by Teshim et al. (1997) from the $n$-butanol extract of the stems and leaves of $C$. nutans. The medicinal properties of vitexin have been reported in many works that claimed that the compound possess antioxidant, anti-tumor, antiinflammatory, anti-viral and anti-depressant activities (Can et al., 2013; Peng et al., 2008; Prabhakar et al., 1981; Zhou et al., 2009). Meanwhile the ion fragments pattern obtained for isoschaftoside was similar to that reported by Simirgiotis et al. (2013) at $\mathrm{m} / \mathrm{z} 353$, 383 and 443 . For the isoorientin that has molecular anion at $m / z$ 448 shown ion fragments at $m / z 327$ and 357 .

On the other hand, a group of flavanone glycosides was identified, such as 2,6-dihydroxyflavanone and 3-hydroxy-3', $4^{\prime}, 5^{\prime}$ trimethoxyflavone that identified at $\mathrm{m} / \mathrm{z} 255$ and $\mathrm{m} / \mathrm{z} 297$, respectively that have been claimed to possess anti-inflammatory effect (Lin et al., 2012). In addition, flavan-3-ol a type of natural phenols and antioxidant i.e., catechin and gallic acid were identified in 50\% v/v extract at $m / z 245$ and 193, respectively. Nevertheless, these compounds were not found in $86 \% \mathrm{v} / \mathrm{v}$ but the presence of kaempferol-7-neohesperidoside might increase the value-added of the extract. The variation of compounds found in both ethanolic extracts was probably due to their different solubility properties in ethanol/water.

\section{Conclusions}

Extraction of compounds of interest from $C$. nutans is highly dependent on the nature of the solvent and the extraction method. The highest total phenols and flavonoid content (i.e., $11.30 \pm 0.39 \mathrm{mg}$ GAE/g DM and $4.66 \pm 0.22 \mathrm{mg}$ QE/g DM, respectively) was obtained with MAE. These values were increased to $14.56 \pm 0.77 \mathrm{mg} \mathrm{GAE} / \mathrm{g}$ DM for total phenols and $5.29 \pm 0.30 \mathrm{mg}$ QE/g DM for flavonoids when P-MAE was applied. Extraction of phytosterols including $\beta$-sitosterol was successful when using SFE with maximal yields as high as $1.35 \pm 0.12 \mathrm{mg}$ of phytosterols $/ \mathrm{g}$ $\mathrm{DM}$ and $0.83 \pm 0.10 \mathrm{mg}$ of $\beta$-sitosterol $/ \mathrm{g}$ DM. In contrast, extracts obtained with the conventional Soxhlet method were very poor in minority bioactive compounds.

Microwave pre-treatment enhanced the extraction of phenols and flavonoids from $C$. nutans medicinal plant whereas for the extraction of phytosterols, SFE was found to be superior to microwave and Soxhlet. MAE produced a comparable total extraction yield to Soxhlet whilst SFE yielded the lowest yield among the extraction methods studied. Pressurized microwave-assisted extraction (P-MAE) merely enhanced the total extraction yield and polyphenols content of ambient pressure MAE without variations in the range of compounds extracted. Therefore, the comparison of MAE, SFE and Soxhlet extraction showed that MAE technique was more efficient than Soxhlet methods for the extraction of $C$. nutans in a shorter time, with reasonable yield and high content of compounds interest, particularly of polar polyphenols.
C. nutans extracts are rich of chlorophyll and contained abundant nutraceutical compounds, mainly phytol, palmitic acid, polyphenols, flavonoids and phytosterols. Thus, $C$. nutans extract has a great potential to be used as a source of natural bioactive, nutraceutical compounds. High phenolic compounds qualitatively screened by UPLC-ESI-QTOF/MS in the $50 \% \mathrm{v} / \mathrm{v}$ ethanolic extract rather than $86 \% \mathrm{v} / \mathrm{v}$ showed that $50-50$ is the best ethanol-water composition to extract polyphenols from C. nutans medicinal plant. Nevertheless, further investigation on the antioxidant and antimicrobial activity of the recovered phytocompounds obtained by microwave pre-treatment is essential to determine the bioactive activity of the extracts.

\section{Acknowledgements}

A. N. Mustapa acknowledges a sponsorship of the program from Ministry of Education (MOE), Malaysia, supported together with Universiti Teknologi MARA (UiTM). Á. Martín thanks the Spanish Ministry of Economy and Competitiveness for a Ramón y Cajal research fellowship. This work has been financed by Junta de Castilla y León (Spain) through project VA330U13.

\section{References}

Agoramoorthy, G., Chandrasekaran, M., Venkatesalu, V., Hsu, M.J., 2007. Antibacterial and antifungal activities of fatty acid methyl esters of the blind-your-eye mangrove from India. Braz. J. Microbiol. 38, 739-742.

Araújo, L.B.D.C., Silva, S.L., Galvão, M.A.M., Ferreira, M.R.A., Araújo, E.L., Randau, K.P., Soares, L.A.L., 2013. Total phytosterol content in drug materials and extracts from roots of Acanthospermum hispidum by UV-vis spectrophotometry. Rev. Bras. Farmacogn. 23, 736-742.

de Arevalo, A.M., 2008. Phytosterol Enrichment in Vegetable Oil by High Pressure Processing. Shaker Verlag GmbH, Hamburg-Harburg, Germany.

Aspé, E., Fernández, K., 2011. The effect of different extraction techniques on extraction yield total phenolic, and anti-radical capacity of extracts from Pinus radiata Bark. Ind. Crop. Prod. 34, 838-844.

Beveridge, T.H.J., Li, T.S.C., Drover, J.C.G., 2002. Phytosterol content in American Ginseng seed oil. J. Agr. Food Chem. 50, 744-750.

Brahmi, F., Mechri, B., Dabbou, S., Dhibi, M., Hammami, M., 2012. The efficacy of phenolics compounds with different polarities as antioxidants from olive leaves depending on seasonal variations. Ind. Crop. Prod. 38, 146-152.

Can, Ö.D., Demir Özkay, Ü., Üçel, U.i.., 2013. Anti-depressant-like effect of vitexin in $\mathrm{BALB} / \mathrm{c}$ mice and evidence for the involvement of monoaminergic mechanisms. Eur. J. Pharmacol. 699, 250-257.

Carretero, M.E., Lopez-Perez, J.L., Abad, M.J., Bermejo, P., Tillet, S., Israel, A., Noguera, P.B., 2008. Preliminary study of the anti-inflammatory activity of hexane extract and fractions from Bursera simaruba (Linneo) Sarg (Burseraceae) leaves. J. Ethnopharmacol. 116, 11-15.

Charuwichitratana, S., Wongrattanapasson, N., Timpatanapong, P., Bunjob, M., 1996. Herpes zoster: treatment with Clinacanthus nutans cream. Int. J. Dermatol. 35, 665-666.

Chung, Y.C., Chang, C.T., Chao, W.W., Lin, C.F., Chou, S.T., 2002. Antioxidative activity and safety of the 50 ethanolic extract from red bean fermented by Bacillus subtilis IMR-NK1. J. Agric. Food Chem. 50, 2454-2458.

Dampawan, P., Huntrakul, C., Reutrakul, V., Raston, C.L., White, A.H., 1977. Bioorganic \& medicinal chemistry journal of $\mathrm{CO}_{2}$ utilization constituents of Clinacanthus nutans and crystal-structure of lup-20(29)-ene-3-one. J. Sci. Soc. Thailand 3, 14-26.

Dashwood, R., 1997. Chlorophylls as anticarcinogens (review). Int. J. Oncol. 10, 721-727.

Europe, M.S.D.S., 1994. Europe MSDS. Murtagh \& Associates, United States.

European Medicines Agency, 2010. In: Agency, E.M. (Ed.), European Medicines Agency. Ethanol Content in Herbal Medicinal Products and Traditional Herbal Medicinal Products Used in Children. Science Medicine Health, London, pp. $1-8$.

Ezhilan, B.P., Neelamegam, R., 2012. GC-MS analysis of phytocomponents in the ethanol extract of Polygonum chinense L. Pharmacogn. Res. 4, 11-14.

Ferruzzi, M.G., Blakeslee, J., 2007. Digestion absorption, and cancer preventative activity of dietary chlorophyll derivatives. Nutr. Res. 27, 1-12.

Galanakis, C.M., Goulas, V., Tsakona, S., Manganaris, G.A., Gekas, V., 2013. A knowledge base for the recovery of natural phenols with different solvents. Int. J. Food Prop. 16, 382-396.

Ho, S.Y., Tiew, W.P., Priya, M., Mohamed, S.A.S., Gabriel, A.A., 2013. Phytochemical analysis and antibacterial activity of methanolic extract of Clinacanthus nutans leaf. Int. J. Drug Dev. Res. 5, 229-233.

Huang, W.Y., Cai, Y.Z., Zhang, Y., 2010. Natural phenolic compounds from medicinal herbs and dietary plants: potential use for cancer prevention. Nutr. Cancer 62, 1-20. 
Janwitayanuchit, W., Suwanborirux, K., Patarapanich, C., Pummangura, S., Lipipun, V., Vilaivan, T., 2003. Synthesis and anti-herpes simplex viral activity of monoglycosyl diglycerides. Phytochem 64, 1253-1264.

Katona, B.G., Siegel, E.G., Cluxton Jr, R.J., 1987. The new black magic: activated charcoal and new therapeutic uses. J. Emerg. Med. 5, 9-18.

Kazan, A., Koyu, H., Turu, I.C., Yesil-Celiktas, O., 2014. Supercritical fluid extraction of Prunus persica leaves and utilization possibilities as a source of phenolic compounds. J. Supercrit. Fluids 92, 55-59.

Koolen, H.H.F., da Silva, F.M.A., Gozzo, F.C., de Souza, A.Q.L., de Souza, A.D.L., 2013. Antioxidant: antimicrobial activities and characterization of phenolic compounds from buriti (Mauritia flexuosa L.f.) by UPLC-ESI-MS/MS. Food Res. Int. 51, 467-473.

Le Floch, F., Tena, M.T., Rí́os, A., Valcárcel, M., 1998. Supercritical fluid extraction of phenol compounds from olive leaves. Talanta 46, 1123-1130.

Li, X., Xiong, Z., Ying, X., Cui, L., Zhu, W., Li, F., 2006. A rapid ultra-performance liquid chromatography-electrospray ionization tandem mass spectrometric method for the qualitative and quantitative analysis of the constituents of the flower of Trollius ledibouri Reichb. Anal. Chim. Acta 580, 170-180.

Lin, J.-A., Wu, C.H., Fang, S.C., Yen, G.C., 2012. Combining the observation of cell morphology with the evaluation of key inflammatory mediators to assess the anti-inflammatory effects of geranyl flavonoid derivatives in breadfruit. Food Chem. 132, 2118-2125.

Lin, J., Li, H.M., Yu, J.G., 1983. Studies on the chemical constituents of niu xu hua (Clinacanthus nutans). Zhongcaoyao 14, 337-338.

Liu, W., Ding, B., Ruan, X.M., Xu, H.T., Yang, J., Liu, S.M., 2007. Analysis of free and conjugated phytosterols in tobacco by an improved method using gas chromatography-flame ionization detection. J. Chromatogr. A 1163, 304-311.

Llaverias, G., Escolà-Gil, J.C., Lerma, E., Julve, J., Pons, C., Cabré, A., Cofán, M., Ros, E., Sánchez-Quesada, J.L., Blanco-Vaca, F., 2013. Phytosterols inhibit the tumor growth and lipoprotein oxidizability induced by a high-fat diet in mice with inherited breast cancer. J. Nutr. Biochem. 24, 39-48.

Mabry, T.J., Markham, K.R., Thomas, M.B., 1970. The Systematic Identification of Flavonoids. Springer Verlag, New York.

Mendiola, J.A., Santoyo, S., Cifuentes, A., Reglero, G., Ibanez, E., Senorans, F.J., 2008 Antimicrobial activity of sub- and super-critical $\mathrm{CO}_{2}$ extracts of the green alga Dunaliella salina. J. Food Prot. 71, 2138-2143.

Nováková, L., Vildová, A., Mateus, J.P., Gonçalves, T., Solich, P., 2010. Development and application of UHPLC-MS/MS method for the determination of phenolic compounds in chamomile flowers and chamomile tea extracts. Talanta 82 , $1271-1280$.

Pejin, B., Ciric, A., Glamoclija, J., Nikolic, M., Sokovic, M., 2014. In vitro anti-quorum sensing activity of phytol. Nat. Prod. Res. 29, 374-377.

Peng, X., Zheng, Z., Cheng, K.W., Shan, F., Ren, G.X., Chen, F., Wang, M., 2008. Inhibitory effect of mung bean extract and its constituents vitexin and isovitexin on the formation of advanced glycation endproducts. Food Chem. 106, 475-481.

Prabhakar, M.C., Bano, H., Kumar, I., Shamsi, M.A., Khan, M.S., 1981 Pharmacological investigations on vitexin. Planta Med. 43, 396-403.

Putwatana, P., Sanmanowong, P., Oonprasertpong, L., Junda, T., Pitiporn, S., Narkwong, L., 2009. Relief of radiation-induced oral mucositis in head and neck cancer. Cancer Nurs. 32, 82-87.

Queimada, A.J., Mota, F.L., Pinho, S.P., Macedo, E.A., 2009. Solubilities of biologically active phenolic compounds: measurements and modeling. J. Phys. Chem. B 113, 3469-3476.

Rao, C.V., Newmark, H.L., Reddy, B.S., 1998. Chemopreventive effect of squalene on colon cancer. Carcinogenesis 19, 287-290.

Ritchie, R.J., 2008. Universal chlorophyll equations for estimating chlorophylls a, b, $\mathrm{c}$, and $\mathrm{d}$ and total chlorophylls in natural assemblages of photosynthetic organisms using acetone, methanol, or ethanol solvents. Photosynthetica 46 , 115-126.

Rombaut, N., Savoire, R., Thomasset, B., Bélliard, T., Castello, J., Van Hecke, É., Lanoisellé, J.L., 2014. Grape seed oil extraction: interest of supercritical fluid extraction and gas-assisted mechanical extraction for enhancing polyphenol co-extraction in oil. C. R. Chim. 17, 284-292.

Sajfrtová, M., Ličková, I., Wimmerová, M., Sovová, H., Wimmer, Z., 2010. $\beta$-Sitosterol: supercritical carbon dioxide extraction from sea buckthorn (Hippophae rhamnoides L.) seeds. Int. J. Mol. Sci. 11, 1842-1850.
Sajfrtová, M., Sovová, H., Opletal, L., Bártlová, M., 2005. Near-critical extraction of $\beta$-sitosterol and scopoletin from stinging nettle roots. J. Supercrit. Fluids 35 , 111-118.

Sakdarat, S., Shuyprom, A., Pientong, C., Ekalaksananan, T., Thongchai, S., 2009. Bioactive constituents from the leaves of Clinacanthus nutans Lindau. Bioorg. Med. Chem. 17, 1857-1860.

Saleem, M., 2009. Lupeol, a novel anti-inflammatory and anti-cancer dietary triterpene. Cancer Lett. 285, 109-115.

Sanjaya, R.E., Tedjo, Y.Y., Kurniawan, A., Ju, Y.H., Ayucitra, A., Ismadji, S., 2014. Investigation on supercritical $\mathrm{CO}_{2}$ extraction of phenolic-phytochemicals from

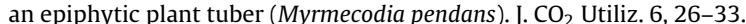

Simirgiotis, M., Schmeda-Hirschmann, G., Bórquez, J., Kennelly, E., 2013. The Passiflora tripartita (banana passion) fruit a source of bioactive flavonoid C-glycosides isolated by HSCCC and characterized by HPLC-DAD-ESI/MS/MSI. Mol. (Base Switzerland) 18, 1672-1692.

Sólyom, K., Solá, R., Cocero, M.J., Mato, R.B., 2014. Thermal degradation of grape marc polyphenols. Food Chem. 159, 361-366.

Sovová, H., 2005. Mathematical model for supercritical fluid extraction of natural products and extraction curve evaluation. J. Supercrit. Fluids 33, 35-52.

Spigno, G., Tramelli, L., De Faveri, D.M., 2007. Effects of extraction time, temperature and solvent on concentration and antioxidant activity of grape marc phenolics. J. Food Eng. 81, 200-208.

Teshim, K.I., Kaneko, T., Ohtani, K., Kasai, R., Lhieochaiphant, S., Picheansoonthon, C., Yamasaki, K., 1997. C-Glycosyl flavones from Clinacanthus nutans. Nat. Med. 51, 557.

Teshima, K.I., Kaneko, T., Ohtani, K., Kasai, R., Lhieochaiphant, S., Picheansoonthon, C., Yamasaki, K., 1998. Sulfur-containing glucosides from Clinacanthus nutans. Phytochemistry 48, 831-835.

Tiew, W.P., P'ng, X.W., Chin, J.H., Gabriel, A.A., 2014. Effect of methanol extract of Clinacanthus nutans on serum biochemical parameters in rats. J. Appl. Pharm. 6, 77-86.

Tuntiwachwuttikul, P., Pootaeng-On, Y., Phansa, P., Taylor, W.C., 2004 Cerebrosides and a monoacylmonogalactosylglycerol from Clinacanthus nutans. Chem. Pharm. Bull. 52, 27-32.

Wanikiat, P., Panthong, A., Sujayanon, P., Yoosook, C., Rossi, A.G., Reutrakul, V., 2008. The anti-inflammatory effects and the inhibition of neutrophil responsiveness by Barleria lupulina and Clinacanthus nutans extracts. J. Ethnopharmacol. 116, 234-244.

Wellburn, A.R., 1994. The spectral determination of chlorophylls a and b, as well as total carotenoids, using various solvents with spectrophotometers of different resolution. J. Plant Physiol. 144, 307-313.

Wintermans, J.F., de Mots, A., 1965. Spectrophotometric characteristics of chlorophylls a and b and their pheophytins in ethanol. Biochim. Biophys. Acta 109, 448-453.

Xiao, X.H., Yuan, Z.Q., Li, G.K., 2013. Preparation of phytosterols and phytol from edible marine algae by microwave-assisted extraction and high-speed counter-current chromatography. Sep. Purif. Technol. 104, 284-289.

Yong, Y.K., Tan, J.J., Teh, S.S., Mah, S.H., Ee, G.C.L., Chiong, H.S., Ahmad, Z., 2013. Clinacanthus nutans extracts are antioxidant with antiproliferative effect on cultured human cancer cell lines. J. Evid. Based Complement. Altern. Med. 2013, 8.

Yoosook, C., Panpisutchai, Y., Chaichana, S., Santisuk, T., Reutrakul, V., 1999. Evaluation of anti-HSV-2 activities of Barleria lupulina and Clinacanthus nutans. J. Ethnopharmacol. 67, 179-187.

Yuann, J.-M.P., Wang, J.-S., Jian, H.-L., Lin, C.-C., Liang, J.-Y., 2012. Effects of Clinacanthus nutans (Burm.f) Lindau leaf extracts on protection of plasmid DNA from riboflavin photoreaction. MC-Trans. Biotechnol. 4, 45-58.

Zhang, W., Xu, M., Yu, C., Zhang, G., Tang, X., 2010. Simultaneous determination of vitexin-4-O-glucoside, vitexin-2-O-rhamnoside, rutin and vitexin from hawthorn leaves flavonoids in rat plasma by UPLC-ESI-MS/MS. J. Chromatogr. B Anal. Technol. Biomed. Life Sci. 878, 1837-1844.

Zhou, Y., Liu, Y.E., Cao, J., Zeng, G., Shen, C., Li, Y., Zhou, M., Chen, Y., Pu, W., Potters, L., Shi, Y.E., 2009. Vitexins, nature-derived lignan compounds, induce apoptosis and suppress tumor growth. Clin. Cancer Res. 15, 5161-5169. 